\title{
MUDANÇAS NAS TRAJETÓRIAS DE VIDA E IDENTIDADES DE MULHERES NA CONTEMPORANEIDADE
}

\author{
Carolina de Campos Borges ${ }^{*}$
}

\begin{abstract}
RESUMO. Este artigo apresenta os resultados de uma pesquisa realizada no Rio de Janeiro e discute mudanças nas trajetórias de vida de mulheres das classes médias nas últimas décadas. Foram entrevistadas sobre seus projetos de vida dez mulheres pertencentes a duas gerações. Todas as entrevistas foram gravadas e transcritas na íntegra. Os textos resultantes das transcrições foram submetidos a uma análise de discurso. $O$ estudo indicou que o aprofundamento do individualismo na vida social contemporânea vem alterando os projetos de vida dos indivíduos. As trajetórias de vida das mulheres são hoje menos padronizadas; trabalho, profissão e independência financeira são temas que têm ganhado relevância nos seus projetos. Nesse contexto, a identidade feminina é cada vez menos influenciada pelos papéis familiares tradicionais.
\end{abstract}

Palavras-chave: Mulher; trajetória de vida; identidade.

\section{CHANGES IN THE PATHS OF LIFE AND IDENTITIES OF WOMEN IN THE CONTEMPORARY WORLD}

\begin{abstract}
This paper presents the results of a research carried out in Rio de Janeiro. It discusses the changes in the paths of lives of middle-class women in the last decades. A group of ten women belonging to two generations was interviewed regarding their life projects. All interviews were recorded and transcribed. Discourse analysis was performed on the resulting texts. The study has indicated that the growing individualism in the contemporary social life is altering the life projects of individuals. Today, the women's paths of life are less standardized; work, profession and financial independence are issues that have gained prominence in their projects. In this context, the female identity is less influenced by traditional family roles.
\end{abstract}

Key words: Women; paths of life; identity.

\section{CAMBIOS EN LAS TRAYECTORIAS DE VIDA E IDENTIDADES DE LAS MUJERES EN LA CONTEMPORANEIDAD}

RESUMEN. Este artículo presenta los resultados de una investigación realizada en Rio de Janeiro y discute los cambios en las trayectorias de vida de mujeres de clase media en las últimas décadas. 10 mujeres pertenecientes a dos generaciones fueron entrevistadas sobre sus proyectos de vida. Todas las entrevistas fueron grabadas y transcritas. Los textos resultantes de las transcripciones fueron sometidos a un análisis del discurso.El estudio indicó que el énfasis en el individualismo en la vida social contemporánea viene alterando los proyectos de vida de los individuos. Las trayectorias de vida de las mujeres siguen menos, hoy en día, un patrón y temas como el trabajo, la profesión y la independencia financiera han ganado relevancia en sus proyectos de vida. En este contexto, la identidad femenina es cada vez menos influenciada por papeles familiares tradicionales.

Palabras-clave: Mujer; trayectoria de vida; identidad.

Este artigo discute algumas mudanças que atualmente vêm ocorrendo na vida das mulheres das camadas médias, com base nos dados de uma pesquisa realizada na cidade do Rio de
Janeiro, na qual foram analisados os discursos de dez mulheres, pertencentes a duas gerações diferentes, sobre seus projetos de vida. Os resultados deste estudo apontaram uma

Doutora em Psicologia pela Universidade Católica do Rio de Janeiro (PUC-Rio), com pós-doutorado em Análise de Discurso pela Université Sorbonne Nouvelle (Paris 3 - Paris/França). Professora Adjunta do curso de psicologia da Universidade Federal da Grande Dourados (UFGD/MS). 
significativa mudança na maneira como elas se engajavam na construção de suas trajetórias de vida três décadas atrás e na forma como isso acontece atualmente. A diferença se refere principalmente a suas expectativas em relação ao casamento e à vida profissional e aos distintos modelos sociais de identidade feminina perseguidos por elas.

As alterações nos horizontes de mulheres na contemporaneidade são tomadas neste estudo como reflexo das amplas transformações socioculturais que marcam os tempos atuais. Por isso, para debater este tema tomamos a perspectiva da trajetória de vida como viés de análise, apreendendo, assim, o desenrolar da vida de cada indivíduo como algo codificado e organizado social e culturalmente.

As trajetórias de vida, conforme Lalive D’Epinay, Bickel, Cavalli \& Spini (2005), são definidas como uma dimensão própria da estrutura social por serem elas reguladas por modelos e padrões socialmente produzidos. Tais modelos e padrões delimitam as possibilidades de ação dos indivíduos, pois, mesmo que eles tenham uma margem de manobra de suas vidas, suas ações são sempre influenciadas pelos códigos simbólicos compartilhados em um dado contexto social.

No cenário da contemporaneidade, a exacerbação do valor do individualismo na vida social repercute nos modelos sociais de trajetória de vida socialmente instituídos, portanto, também repercute concretamente nos percursos de vida dos indivíduos. Segundo Cavalli (2003), por um lado está havendo a despadronização da trajetória de vida e, por outro, a desinstitucionalização de um modelo de trajetória de vida rigidamente padronizado, ou, em outras palavras, a institucionalização de um modelo de trajetória de vida individualizado.

Despadronização das trajetórias de vida refere-se à transformação dos padrões que estruturavam as trajetórias de vida seguidas pelos indivíduos, permitindo maiores variações entre seus percursos de vida. Desinstitucionalização da trajetória de vida diz respeito a mudanças operadas no enquadramento normativo das vidas individuais (Cavalli, 2003).

De acordo com Widmer, Levy \& Gauthier (2006), nas diversas sociedades geralmente são produzidos pelo menos dois modelos de trajetória de vida, um para cada sexo. As trajetórias de vida de mulheres são geralmente distintas das trajetórias masculinas em consequência da lógica de participação social diferente para cada gênero, ou seja, da institucionalização de papéis sociais distintos para eles e elas e da atribuição de características e funções diferentes para homens e para mulheres.

Cavalli (2003) ressalta que desde algumas décadas vem-se observando uma transformação daquilo que antigamente se apresentava como específico de mulheres e de homens, gerando novos ajustes nos padrões femininos e masculinos estabelecidos. Com isso vem ocorrendo uma aproximação das trajetórias de vida masculinas e femininas, que tendem a se tornar mais parecidas, mas - é claro - sem que desapareçam todas as diferenças nas formas de inserção social de mulheres e homens.

Justamente, uma reformulação dos modelos sociais de trajetória de vida instituídos para mulheres também foi constatada no estudo por nós realizado. Segundo nossos dados, tal reformulação está diretamente ligada à revisão de discursos sociais que afirmam serem temas centrais em suas vidas o casamento e a família. Atualmente o casamento vem deixando de ocupar o centro nos projetos das mulheres, diferentemente do que acontecia antigamente, enquanto 0 trabalho, a profissão e a independência financeira, assuntos tradicionalmente masculinos, estão sendo cada vez mais valorizados por elas. Como reflexo de tais mudanças nos projetos e trajetórias das mulheres, verificam-se mudanças na subjetividade feminina, com a emersão de um novo ideal social de mulher.

Para discutir estes resultados, neste artigo serão primeiramente explicitados os procedimentos metodológicos utilizados nesta investigação; em seguida serão apresentados os resultados da pesquisa, especialmente os dados sobre as mudanças nos projetos e nas trajetórias de vida das mulheres apreendidas por meio da análise de discurso realizada; e finalmente, serão debatidas as implicações que tais mudanças têm para o modelo de identidade feminina produzido na contemporaneidade.

\section{MÉTODO}

Esta pesquisa foi realizada seguindo as premissas da Análise de Discurso. Segundo Rocha-Coutinho (1998), a "Análise de Discurso" 
tem suas origens no campo da linguística, mas é interessante para a psicologia quando se tem como propósito realizar estudos psicossociais. Como ressalta Fairclough (2001), a linguagem é um processo social influenciado pelas interações com outros processos sociais. Nessa perspectiva, pelo reconhecimento de que as mudanças no uso linguístico estão ligadas a processos socioculturais mais amplos, pode-se estudar o processo de mudança social.

O estudo foi aprovado pelo Comitê de Ética em Pesquisa da Pontifícia Universidade Católica do Rio de Janeiro, mediante o Protocolo $\mathrm{n}^{\circ}$ 02A/2008, em 12 de junho de 2008, e todos os participantes assinaram um termo de consentimento livre e esclarecido antes do início das entrevistas. Para assegurar o sigilo quanto às identidades das participantes, os nomes utilizados na apresentação dos resultados desta pesquisa são fictícios.

Foram realizadas entrevistas semiestruturadas com dez mulheres, das quais dez eram da geração mais velha (com idades entre 63 e 69 anos) e dez da geração mais jovem (com idades entre 27 e 34 anos), todas pertencentes às camadas sociais médias da cidade do Rio de Janeiro, moradoras de bairros da Zona Sul. As faixas etárias das participantes foram definidas em função do objetivo de confrontar as experiências de pessoas de diferentes gerações, considerando-se esta uma maneira de se apreenderem as mudanças sociais (Mannheim, 1982).

A escolha dos sujeitos da pesquisa se deu mediante os seguintes critérios: pertencer aos estratos sociais médios; ter nascido na cidade do Rio de Janeiro e nela ter vivido a maior parte de sua vida. Nenhuma outra condição, como estado civil, morar ou não com a família, ter filhos, etc, foi previamente estabelecida; mas ressalta-se que a ocorrência de pessoas solteiras e sem filhos na geração de 27 a 34 anos pode ter influenciado os resultados obtidos neste estudo.

Os sujeitos foram convidados a participar da pesquisa a partir de sua rede social. Essa é uma estratégia de recrutamento que, segundo Heilborn (2004), serve para que se tenha acesso a um material minimamente controlado quando se têm como alvo as camadas médias, um segmento extremamente vasto e variado e de difícil definição. Trata-se de uma tentativa de abordar pessoas que compartilham de uma representação de mundo próxima dentro das "classes médias", de forma que seja possível a comparação de seus discursos.

Os entrevistados foram convidados a falar livremente sobre seus projetos de vida. No caso das pessoas da geração mais velha, buscou-se conhecer os projetos de vida que tinham quando eram jovens, enquanto os entrevistados da geração mais jovem foram indagados sobre seus projetos de vida atuais. As entrevistas foram realizadas nas casas dos entrevistados e duraram cerca de uma hora. Elas foram gravadas em arquivo de $\mathrm{mp} 3$, de modo que, posteriormente, pudessem ser transcritas na íntegra.

Os textos resultantes das entrevistas foram submetidos a uma análise de discurso. Essa metodologia foi considerada adequada para a realização desta pesquisa em função do nosso objetivo de apreender as falas dos sujeitos como textos produzidos dentro de um contexto sociocultural e explorar os sistemas ideológicos subjacentes a ele. Acrescenta-se que a análise das entrevistas foi influenciada pela Sociologia Compreensiva (Kaufmann, 2007b), especialmente no que diz respeito à fina articulação entre o trabalho de campo realizado e a emersão das categorias de análise. De acordo com as diretrizes gerais desta metodologia, a tarefa do pesquisador é articular equilibradamente teorização e observação, formulando hipóteses a partir do contato com o campo de pesquisa, ou seja, explorando uma problemática que emerge do contato do pesquisador com o campo de pesquisa.

\section{RESULTADOS}

Os resultados da análise dos discursos apontaram diferenças significativas nos projetos de vida das mulheres das duas gerações entrevistadas. Observou-se que, enquanto para as mulheres da geração mais velha o casamento era o acontecimento principal nos seus projetos e trajetórias de vida, para as da geração mais jovem a busca pela realização profissional e pela liberdade individual tem ganhado mais destaque nos seus planos para o futuro.

Por meio dos discursos das entrevistadas da geração mais velha pode-se ver que casamento e constituição de uma família tinha uma importância central nos seus projetos e trajetórias de vida, bem como para a estruturação de suas identidades: 
"A minha geração, eu acho... aquela coisa do príncipe encantado, beija e a princesa acorda, sabe? $E$ foram felizes para sempre... A gente era criada nessa geração lendo "Carmem da Silva" na revista "Cláudia". "A mulher tem que ficar bonitinha pro marido chegar"; "Ah, eu vou fazer faculdade enquanto não me casar', porque se eu tivesse me casado eu não teria feito faculdade (...)" (Francisca, 65 anos, separada, professora de História)

“... sei lá se isso é inerente à mulher e ao jovem, mas eu sempre quis ter uma família. Eu queria me casar, ter filhos. (...) Eu nem sei se naquela época a gente pensava em algum significado. Eu achava que (casar e ter filhos) era uma coisa meio automática. No meu caso, acabei o clássico. Eu já namorava o meu namorado, o meu marido, há cinco anos. (...) Sei lá, como se aquilo fosse embutido, que eu tinha que me casar. $E$ aquele era o rapaz, todo mundo conhecia. Nem apaixonada por ele eu era... Então, eu me casei porque achava que era uma consequência de vida. Chegava naquela idade, a única coisa que eu queria, e eu queria ter filho logo." (Gilda, 65 anos, separada, não terminou a faculdade)

Lançar-se "automaticamente", "naturalmente" ao projeto de constituir uma família remete exatamente à centralidade da família na vida social naquele contexto. Devido ao tipo de laço social fundado, eram poucas as possibilidades de individualização das trajetórias de vida e, por isso, dispensável muita reflexão acerca da decisão de se casar e ter filhos.

Trabalho e profissão ficavam em segundo plano na vida da maioria das mulheres, embora esse padrão já estivesse começando a se transformar, como se pode observar:

"Minha família incentivava o curso
superior. (...) Minha irmã fez Biologia...
Mas eu já era mais aquela coisa: "Ah, eu
quero ir pra PUC, sabe? Vou fazer
História! Não me casei ainda, mas... o
que eu queria era casar. Hahahaha."
(Francisca, 65 anos, separada,
professora de História)

O acesso das mulheres aos estudos de nível superior é considerado por diversos autores como um fator transformador dos padrões sociais dos anos 1950 e 1960, pois, além de enriquecimento cultural, a possibilidade de aprender um ofício e de ter uma profissão afetava inelutavelmente a posição da mulher em relação a seu marido, sua família e toda a sociedade; mas isso não ocorreu rapidamente. Inicialmente, o ingresso das mulheres na vida universitária se deu permeada de preconceitos relacionados à imagem tradicionalmente atribuída à mulher. Por isso havia críticas quanto à presença de mulheres em cursos como direito, medicina ou engenharia. $O$ esperado era que elas se dirigissem mais às faculdades de filosofia para que depois pudessem ingressar no professorado de ginásio, do curso clássico ou científico, como se pode ver na fala de Antônia:

"Eu sempre quis ser arquiteta. Desde pequena eu gostava de desenhar. Aí, com 15 anos, eu comecei a namorar firme um rapaz de engenharia. $E O$ namoro ficou muito sério e... nessa época eu tava no $4^{\circ}$ ano ginasial. $E$ como a gente tinha resolvido se casar, ele disse que eu não ia terminar a faculdade de arquitetura. Então, ao invés de fazer o científico, que eu fizesse o clássico, porque no clássico a gente aprendia línguas. $E$ ele disse que eu, sabendo línguas, ia ajudar a ele na tradução dos livros; e aí eu fui fazer o clássico, mas sempre revoltada, porque eu queria fazer mesmo era arquitetura. Era o sonho que eu tinha. (...) Eu aprendi corte e costura porque ele impôs... aí voltei pra Aliança Francesa continuar estudando francês. Ele queria, assim, uma dona de casa... bem aprimorada, né? Saber cozinhar, saber falar línguas, saber costurar... tudo que eu não queria. Destesto costura! Tenho horror a costurar." (Antônia, 63 anos, solteira, arquiteta)

Apesar das novas perspectivas que se abriam para as mulheres nesse período, 0 padrão de mulher "mãe-esposa-dona-de-casa" continuava forte para esta geração de mulheres. De acordo com Rocha-Coutinho (1994), até o início dos anos 1960 uma carreira profissional era algo praticamente inconcebível para uma mulher, mesmo que já tivesse frequentado uma universidade. Era considerado inapropriado que uma mulher fosse superior a um homem em termos financeiros, de inteligência ou de força física. Elas eram desencorajadas a investir em 
uma profissão, de modo que seu papel social mais importante continuava sendo o de "rainha do lar".

Embora padrões "tradicionais" permanecessem vivos, nesse momento já começava a florescer 0 ideal de felicidade individual, trazendo conflitos, sobretudo para as mulheres das classes média e alta. Como afirmam Mello \& Novais (2010), já se via entre as mulheres algum desejo de trabalhar e ter independência financeira e o inconformismo diante do comportamento sexual dos maridos; mas a busca pelo verdadeiro companheirismo nas relações conjugais ficava muitas vezes camuflada pela necessidade de manter 0 casamento, seja por razões religiosas ou econômicas ou seja por preconceitos sociais.

Diante disso, 0 trabalho assalariado se inseria na vida das mulheres da classe média desta geração de modo "acessório". De acordo com nossas entrevistadas, as tarefas relacionadas ao lar continuavam tendo maior importância, como se pode ver na fala abaixo:

(O trabalho) “(..) tinha alguma importância porque eu ganhava um dinheiro meu, um dinheirinho. Nunca foi muito, porque professora, já viu. Mas o meu trabalho era em função do horário dos meninos. O mais importante eram os meninos. Então, por exemplo, se eles estudassem à tarde, eu trabalhava à tarde. Ser professora tem isso de bom, né? Eu fazia minha vida, dava aula à tarde e (os filhos) estudavam à tarde. Aí de manhã eu ficava por conta deles. Natação, judô, ballet, ginástica rítmica, tudo que eles queriam - médicos, dentistas, aparelhos de dente. Eram eles. Eles, a casa, o marido, passadeira pra camisa do marido ficar bonitinho o colarinho. Ahah. Receitas novas de bolo, de não sei o que." (Francisca, 65 anos, separada, professora de História)

"Se eu tiver que abrir mão de alguma coisa... e já tive, já abri mão... Eu tive o primeiro filho, e quando eu tive o segundo o primeiro tinha um ano e meio só. O $2^{\circ}$ nasceu com a barriga aberta, não fechou. Fez uma cirurgia no dia que nasceu, enfim, teve uns problemas assim. Eu não tive dúvidas de parar de trabalhar. Eu digo: "Não... entre trabalhar e um filho que vai precisar de mim, e o outro que ainda era muito pequenininho, um ano e meio... eu vou parar de trabalhar." Quer dizer, pra mim a família é muito mais importante do que a profissão." (Alda, 65 anos, casada, psicóloga)

Por volta dos anos 1960, um amplo movimento de contestação de padrões sociais e culturais tradicionais propiciou a emersão de uma nova interpretação a respeito da ênfase dada ao papel da mãe, esposa e dona de casa para a subjetividade feminina. A imagem da mulher "rainha do lar" foi contestada como uma forma de enclausuramento da mulher, considerada geradora de desigualdades em relação ao homem - desigualdade de poder, financeira, de responsabilidades domésticas. Em uma sociedade marcada pelo espírito do cálculo, a associação entre trabalho doméstico e gênero feminino propiciou o afastamento da mulher do mundo do trabalho social e economicamente valorizado, numa clara reprodução da dominação masculina na sociedade (Bourdieu, 1998).

Questionamentos sobre a naturalização do padrão de trajetórias de vida para as mulheres centrados nos papéis familiares - logo, do estereótipo da mulher mãe, esposa e dona de casa - contribuíram para a ampliação da ideia de ser mulher. Aos poucos a dimensão da "mulher trabalhadora" e de "mulher com uma carreira profissional" foi se estabelecendo como parte daquilo que compõe a identidade feminina; mas isso - é claro - não aconteceu sem ambivalências, pois associar atividades ditas "masculinas" à mulher impõe mudanças subjetivas profundas (Denefle, 1999). Tanto é assim que, como afirma Singly (2004), homens se disporem a realizar tarefas domésticas e mulheres a executar atividades tradicionalmente atribuídas aos homens quase sempre é entendido como uma "troca" de papéis, guardando bem-marcadas as delimitações dos papéis de homem e de mulher.

Ambivalências à parte, em nosso estudo foram encontradas evidências de transformações nas trajetórias e projetos de vida das mulheres. Embora, como muitos estudos apontam, padrões tradicionais de distinção dos universos masculinos e femininos continuem influenciando os papéis atribuídos a cada gênero (Diehl, 2002; Jablonski, 2010; Rocha-Coutinho, 2005a; 2005b; Féres-Carneiro \& Ziviani, 2009), aos poucos a geração de jovens mulheres vem se distanciando do ideal da mulher "mãe, esposa e dona-de-casa" e desejando, por exemplo, sucesso profissional e financeiro. 
Foi 0 que demonstrou a análise dos discursos das entrevistadas da geração mais jovem. Alcançar independência financeira e se realizar profissionalmente fazem parte das suas preocupações e influenciam suas expectativas para o futuro, como se pode ver baixo:

\begin{abstract}
“... eu me formei, e quando a gente se forma a gente espera que consiga um emprego dentro da nossa área muito rápido. (...) Eu tô trabalhando, mas não é no que eu quero. Quero trabalhar com meio ambiente. (...) Então a minha preocupação no momento é essa. É me estabilizar financeiramente e encontrar alguma coisa que me satisfaça ou não; porque, quem disse que a gente trabalha pra curtir? Não, às vezes a gente trabalha pra ganhar dinheiro e pra comer, sei lá." (Lígia, 33 anos, solteira, formada em Geografia)
\end{abstract}

"Quando eu comecei a fotografar, com 18 anos, isso me deu um desespero muito grande, porque eu não sabia como é que ganhava dinheiro. (...) Então, eu tenho planejamento, mas meu planejamento é $100 \%$ voltado pra minha carreira. (...) Então o meu projeto é, obviamente, estar ganhando bem. (...) 0 meu planejamento é esse. O meu planejamento é tentar colocar o que eu tenho hoje e fazer isso se multiplicar." (Carla, 32 anos, solteira, fotógrafa)

A preocupação de Lígia e Carla em se estabilizar financeiramente, crescer na profissão e ganhar dinheiro aponta para uma significativa transformação no modo de inserção da mulher na sociedade e, consequentemente, em suas trajetórias de vida. Hoje, estabilidade financeira é uma preocupação também para as mulheres, que não veem mais os assuntos do trabalho como algo de segundo plano em suas vidas.

A ambição da mulher no trabalho formal, algo relativamente novo na nossa cultura, remete à desconstrução do padrão fortemente incorporado à nossa sociedade da imagem da mulher como destinada a ser "mãe, esposa e dona-de-casa", dependente financeiramente do marido, e do modelo "homem-provedor e mulherrainha do lar" (Rocha-Coutinho, 1994; Costa, 1989; Maluf \& Mott, 2008). A entrada da mulher no mercado de trabalho e a conquista de sua independência financeira e pessoal propiciam, além da libertação das mulheres de um padrão que, em contexto de valorização da produtividade, tornou-se opressor, a possibilidade de identificação com o trabalho. Com isso, observa-se que o trabalho é hoje, para as mulheres, um valor importante na estruturação de suas identidades pessoais, como se pode ver na fala de Daniela:

"Eu tenho medo de chegar, tipo, aos 40 e tantos anos e ver que eu fiquei fazendo isso, esses trabalhos que não são para mim, sabe? (...) $\mathrm{Na}$ verdade, a minha sensação é que eu não amo o que eu faço. Não é uma coisa que eu faça para mim, mas eu também não sei que coisa seria essa. Eu fiquei tão perdida que teve uma época que eu pensei: cara, o meu talento pode ser pra matemática e eu não sei, cara, comecei a ficar desesperada. Tem uma série de coisas no mundo, como é que eu vou descobrir o que que é? Não sei.(...) Eu fico achando que é meio medíocre eu ficar a vida inteira fazendo uma coisa assim pros outros; um trabalho que é ok, eu faço, eu consigo fazer bem, mas não me desperta nenhuma coisa especial. Mas sem saber que coisa seria, assim. Eu acho muito pobre isso, na verdade." (Daniela, 28 anos, solteira, formada em comunicação social)

Hoje uma profissão é para as mulheres um lugar importante de afirmação de si e de desenvolvimento de seus potenciais - o que é absolutamente contrastante com aqueles discursos que afirmavam ser a mulher naturalmente inapta para o trabalho no âmbito público, e ser o espaço doméstico o único propício à sua realização pessoal. Devido à grande importância atualmente atribuída pelas mulheres ao mundo do trabalho, surge a necessidade de conciliarem as tarefas de casa com as demandas da profissão, como diversos estudos vêm apontando (Rocha-Coutinho, 2007; Losada e Rocha-Coutinho, 2007; Jablonski, 2009; 2010), bem como a de programar a maternidade e até de reduzir o número de filhos, como indicou Scavone (2001).

A necessidade de conciliar funções domésticas e trabalho sinaliza uma nova divisão das responsabilidades entre homens e mulheres na sociedade. Responsabilidade financeira para/com a família atualmente recai também sobre a mulher, como se pode ver no próximo trecho de uma das entrevistas: Eu nunca teria um filho se eu tivesse recebendo mal, num momento financeiro ruim, porque... o que eu 
quero pro meu filho? Educação, que é uma coisa extremamente cara, viagens, experiência de vida, entendeu?" (Lígia, 33 anos, solteira, formada em geografia)

Diante da necessidade de contribuir para a subsistência dos filhos e de progredir no trabalho, a maternidade muitas vezes acaba ficando em segundo plano na vida de algumas mulheres, como é o caso de Patrícia:

"Eu já pensei muito em ter um filho de
qualquer jeito, mas por esse lado
profissional que eu tô te falando, hoje
não tem como ah.. (...); porque, cara, eu
trabalho de seis e trinta da manhã às
onze e trinta da noite e às vezes eu
tenho mais alunos de "personal”. Eu fico
preocupada, que tempo eu vou ter pra
essa criança. Eu não tenho tempo nem
pra almoçar. Quanto mais assim, essa
vida louca e corrida, cada hora tem que
dar aula num lugar, como é que eu vou
colocar uma criança na minha vida? Mas
eu tenho vontade de ter filhos, sabe?"
(Patrícia, 28 anos, solteira, formada em
Educação Física)

Nota-se, assim, que a valorização do trabalho, da profissão e da independência exerce grande impacto na estruturação das trajetórias de vida das mulheres contemporâneas, ao mesmo tempo em que gera um redimensionamento da importância dos papéis de mulher "dona de casa" e de "mãe" na identidade feminina. Ter filhos continua sendo algo almejado pelas mulheres, mas a forma como elas imaginam isso está marcada pelas transformações socioculturais da contemporaneidade.

Conforme os discursos de algumas das jovens adultas entrevistadas, no que se refere ao papel de "esposa", a atribuição de fragilidade aos laços amorosos e às relações conjugais pode estar levando as mulheres a investir menos no casamento, como se observa nos trechos das entrevistas que se seguem:

\footnotetext{
“(...) eu não sei se eu acredito em relacionamento a longo prazo. Eu realmente não sei. Hoje em dia, olhando ao meu redor, eu vejo que as pessoas ficam juntas dez, quinze anos, e se separam. Salvo raríssimas exceções. $E$ essas raríssimas exceções às vezes são hipocrisias, entendeu? São casais que não se gostam mais, mas não se separam por causa da sociedade que vai
}

julgar, sei lá... porque tem medo ou porque a mulher não pode porque não tem condições financeiras de ficar sozinha. Então, eu vejo isso. Eu não quero nunca passar por isso, ficar junto de alguém por hipocrisia, por medo, né? $E$ é isso." (Lígia, 33 anos, solteira, formada em Geografia)

"E eu não sei se é no Rio de Janeiro que acontece isso assim, mas as pessoas são muito... ficam juntos, casam, separam (...) Então, eu também não tenho essa mentalidade do apego. (...) Engraçado, na minha cabeça eu não tenho aquela fantasia do casamento perfeito (...) Os meus pais se casaram. Depois de treze anos de casado se separaram, e depois eu achei que os dois separados era muito melhor do que juntos, sabe?' (Rafaela, 34 anos, solteira, formada em Turismo)

Além disso, parece haver entre as jovens mulheres de hoje o forte desejo de desfrutar de liberdade pessoal, poder viajar, de modo que vínculo conjugal e filhos podem ser entendidos como algo limitador da sua possibilidade de circulação, como se pode ver abaixo:

“... Eu adoro viajar sozinha. Sou do tipo que coloca a mochila nas costas e vou. Passo o final de semana. Como eu tô, muitas vezes, namorando, isso não é uma coisa agradável e nem sempre a galera topa, sabe? (...) "Te adoro, mas o mundo é muito maneiro. Tem um monte de coisa acontecendo. Eu saio, eu viajo". Eu tenho essa coisa de presença, sabe? O mundo só tá acontecendo se eu tô presente nele." (Carla, 32 anos, solteira, fotógrafa)

"Quero aproveitar esses momentos, essa fase que eu posso, assim, independente, muito jovem ainda, que eu posso pensar que eu posso ter um filho daqui a seis anos e tá tranquilo, porque daqui a seis anos eu vou estar com 34. Ok, ter um filho com 34, entendeu? Mas eu quero muito esses seis anos. Eu acho que eles são muito importantes, sabe? Eu jamais faria isso agora (...) Eu até cogito casar, mas não é uma coisa nos próximos anos. É uma coisa que vai estar mais ligada a quando eu tiver mais calma (entre aspas). Eu já me sinto mais calma, mais madura, mas eu ainda acho que é muito importante pra mim fazer as coisas sozinha e ter um pouco de 
liberdade de fazer o que eu quero. Tem dia que eu não quero estar com essa pessoa. Não tem nada de errado nisso, mas eu não quero. E é uma parada que meio que impede muito isso. Você pode até combinar, você sai com Fulano e eu com Beltrano, mas você vai voltar pra dormir na mesma cama necessariamente. Isso é muito radical, assim, pra mim ainda." (Daniela, 28 anos, solteira, formada em Comunicação Social)

Os discursos dessas mulheres sinalizam a ampliação de possibilidades na vida das mulheres, com o enfraquecimento do modelo da mulher mãe, esposa e dona de casa. Ser dona de casa não apetece mais às mulheres contemporâneas como acontecia com mulheres de outras gerações. A dimensão profissional parece ser, no contexto atual, um importante componente da realização pessoal feminina. Não mais inspiradas a serem "rainhas do lar", nem dependentes financeiramente do marido, a pesquisa revelou que as mulheres querem ser donas de suas vidas; e mesmo que continuem querendo ser mães, não acham mais imprescindível o casamento, como se pode ver:

"Tá. O plano de família sempre existiu.
Eu sempre quis ter filhos. (...) Filhos,
família. Marido, não. Assim, marido, se
ele existir, pra mim é 100\% melhor
porque é uma figura que vai me ajudar a
cuidar da família. (Lígia, 33 anos,
solteira, formada em Geografia)

Tipo, não me vejo não tendo filho. (Rafaela, 34 anos, solteira)

Ah, ter uma criança, um filho... Eu acho que se eu não tiver por qualquer motivo vai ser uma frustração. (Patrícia, 28 anos, solteira)

Assim concluiu-se, por meio deste estudo, que vem ocorrendo uma transformação significativa nos parâmetros que definem as trajetórias de vida das mulheres. O padrão mulher "mãe, esposa e dona de casa", a "rainha do lar", que algumas décadas atrás influenciava determinantemente os projetos e trajetórias de vida das mulheres das classes médias, vem influenciando menos os projetos das jovens adultas da contemporaneidade. Trata-se da desinstitucionalização de um modelo de trajetória de vida baseado nesse padrão de mulher e da institucionalização de outro modelo, mais individualizado, menos padronizado, no qual é permitido que as mulheres experimentem papéis antes reservados ao homem, como o de pessoa realizada profissionalmente e bemsucedida financeiramente. Na realidade, persiste a importância da maternidade na vida das mulheres, mas dentro de um contexto menos marcado por imposições sociais - como a obrigatoriedade do casamento -, e mais aberto a motivações de caráter individual.

\section{CONSIDERAÇÕES FINAIS}

Além das mudanças operadas nas trajetórias de vida das mulheres, este estudo aponta que vem se transformando, nas últimas décadas, a identidade feminina. Está emergindo na contemporaneidade um novo "modelo social de mulher", que resulta da superação da histórica associação feita entre "mundo público e masculinidade" e "mundo privado e feminilidade" e da abertura dos processos identitários individuais à lógica da "reflexividade do eu", tal como descreve Giddens (2002).

O padrão da mulher "rainha do lar" foi instituído na sociedade brasileira no século $X X$ sob a influência de ideais individualistas importados da Europa, combinado a ideais familísticos tradicionais brasileiros. Como afirma Costa (1989), desde o período colonial no Brasil, quando surgiam as primeiras cidades, até 0 período moderno, insistiu-se sobre o fato de ser o universo da mulher exatamente o contrário daquele do homem.

A crença em ser a natureza feminina propícia para o desempenho das funções do lar e a natureza masculina apropriada para as funções do mundo público se sustentou, primeiramente, na suposta inferioridade biológica da mulher, a qual limitaria suas condições de realizar outras tarefas que não as de cuidar dos filhos e da casa. Depois, sob a influência de princípios da modernidade, que reivindicavam "igualdade" entre homens e mulheres, o argumento que justificava tal distinção de gênero passou a atribuir à "natureza feminina" características propícias ao mundo doméstico e à "natureza masculina" aquelas necessárias para atuar no mundo público. As mulheres foram consideradas, então, essencialmente sensíveis, frágeis, inadequadas para o trabalho pesado portanto, naturalmente voltadas para a 
maternidade; já os homens - naturalmente racionais, fortes -, em perfeita adequação para o mundo público (Costa, 1989).

No início do século $X X$ o avanço das tecnologias, trazendo para dentro da casa um maquinário que auxiliaria a dona de casa na realização das tarefas mais pesadas e cansativas, impulsionou a formação de uma nova imagem para a mulher, a "mulher moderna", sempre linda e feliz, exímia dona de casa e administradora do lar, detentora de conhecimentos gerais e ainda uma esposa maravilhosa. Surgia, assim, a "rainha do lar", novo ideal de mulher. Mesmo não correspondendo à realidade de mulheres de todos os segmentos sociais, este modelo influenciou profundamente a identidade social das mulheres desse século e é claro - também a do homem, de forma oposta e complementar (Maluf \& Mott, 2008).

A progressiva introdução de um discurso igualitário na sociedade impulsionada pelo movimento feminista nos anos 1970 gerou questionamentos sobre a naturalização das distinções das trajetórias de vida femininas e masculinas e a restrição do mundo público aos homens. Inevitavelmente, tratava-se da desconstrução daquele modelo de mulher inspirado na "rainha do lar", "mãe, esposa e dona de casa", e da ampliação dos seus horizontes de vida. Hoje, novas possibilidades de trajetórias de vida se apresentam para as mulheres e, como demonstraram os resultados desta pesquisa, trabalho, profissão e assuntos financeiros fazem parte de seus interesses.

A desinstitucionalização das trajetórias de vida gera mudanças na institucionalização de um modelo de identidade pessoal. Como enfatizam Kaufmann (2004) e Martucelli \& Singly (2009), dentro de um contexto social fortemente padronizado, o indivíduo se encontra de certa maneira englobado por tradições e convenções sociais, e suas identidades são construídas com base em referências advindas das instituições, em papéis sociais instituídos. Em um contexto onde há maiores possibilidades de individualização, o indivíduo se define pelo distanciamento dos papéis sociais de tipos institucionalmente rígidos e hierarquicamente controlados. Ele se constrói, se define e se engaja na vida de forma inovadora, em resposta à tendência à desarticulação, flexibilização e multiplicidade dos papéis sociais em relação às instituições.
Distinguem-se, assim, conforme Singly (2005) e Martucelli \& Singly (2009), duas modalidades de identidade: uma identidade que se define por estatutos sociais e uma definida pelo reconhecimento pessoal. Na primeira há o "eu estatutário", que corresponde à identidade formada pela identificação com papéis socialmente instituídos; na outra, o "eu pessoal" correspondente a uma representação de si formada a partir do reconhecimento produzido nas relações que estabelece com "outros significativos", pessoas do convívio pessoal, com quem se estabelece relação de intimidade e dentro das quais se é reconhecido como alguém singular e original.

Segundo os autores, na complexa realidade contemporânea, os indivíduos conjugam essas duas formas de processamento identitário, mas a ênfase é dada ao segundo tipo. Assim, a identidade dos indivíduos inclui a dimensão do eu estatutário e a dimensão do eu pessoal. $\mathrm{O}$ processo de individualização depende da capacidade do sujeito de se distanciar de referências socialmente dadas para que possa explorar novas dimensões de si e estabelecer novos vínculos. Ainda que não se elimine a existência da identidade estatutária, ela é uma referência apenas parcial para aquilo que define alguém.

A ideia de um "eu reflexivo" apresentada por Giddens (2002) complementa esta discussão sobre a relação entre desinstitucionalização de trajetórias de vida e de identidades pessoais no cenário contemporâneo. Segundo o autor, em um contexto marcado pela diversificação da vida social, pela pluralidade das referências culturais e pelo esvaziamento das tradições, como é o caso da contemporaneidade, recai sobre os indivíduos a tarefa de se descobrir como alguém singular e original. Por meio de um diálogo - uma reflexão - que eles permanentemente estabelecem consigo mesmos sobre as identificações que fazem, cada indivíduo vai, então, delineando sua identidade, tal como se compõe uma narrativa. É o próprio indivíduo o ponto de sustentação de si mesmo, e cabe a ele a responsabilidade por escolher seus caminhos e construir sua trajetória.

Tudo isso vai ao encontro dos resultados obtidos neste estudo. Retomando o caso das mulheres entrevistadas, verificou-se que elas, desde as últimas décadas, vêm experimentando a desinstitucionalização do rígido e tradicional modelo de trajetória de vida baseado no padrão 
da mulher "rainha do lar". As mulheres adultas de hoje se projetam na esfera pública e consideram a profissão importante para sua realização pessoal, embora não deixem de valorizar também as relações estabelecidas no âmbito privado. Em um mundo de instabilidades nos vínculos amorosos e nas instituições, ter uma profissão pode significar para elas independência financeira, autonomia pessoal, liberdade, maior margem de manobra sobre suas vidas, bem como uma forma diferente de estar presente do mundo.

Desta forma, assiste-se à emersão de um novo ideal social de mulher: uma mulher que preza a individualidade e a liberdade, que quer ser independente pessoal e financeiramente e que deseja se realizar no mundo público. O novo padrão de trajetória de vida das mulheres, calcado na ideia de despadronização, corrobora a institucionalização de uma concepção de mulher definida como sujeito ativo no processo de produção de sua trajetória, portanto, também de si mesma.

\section{REFERÊNCIAS}

Bourdieu, P. (1998). La domination masculine. Paris: Seuil.

Cavalli, S. (2003). Le parcours de vie: entre institutionnalisation et individualisation. In: L'avenir : attentes, projets, (dés)illusions, ouvertures. Lausanne (Suíça) : Editions Réalités Sociales.

Costa, J. F. (1989). Ordem médica e norma familiar. $3^{\text {a }}$ edição. Rio de Janeiro: Graal.

Denefle, S. (1999). De la vie privée au monde du travail : changements de regard sur les femmes dans le dernier tiers. In : A. Guillou \& S. Pennec (orgs.). Les parcours de vie des femmes: travail, familles et représentations publiques. Paris: L'Harmattan.

Diehl, A. (2002). O homem e a nova mulher: novos padrões sexuais de conjugalidade. In: A. Wagner (coord.). Família em cena: tramas, dramas e transformações. Petrópolis, RJ: Vozes.

Fairclough, N. (2001). Discurso e mudança social. Brasília: Editora UnB, 2001.

Féres-Carneiro, T.; Ziviani, C. (2009). Conjugalidades contemporâneas: um estudo sobre os múltiplos arranjos amorosos da atualidade. In: T. Féres-Carneiro (org.). Casal e família: permanências e rupturas. São Paulo: Casa do Psicólogo.

Giddens, A. (2002). Modernidade e identidade. Rio de Janeiro: Jorge Zahar Editora.

Heilborn. M. L. (2004). Dois é par - gênero e identidade sexual em contexto igualitário. Rio de Janeiro: Garamond.

Jablonski, B. (2009). Atitudes e expectativas de jovens solteiros frente à família e ao casamento: duas décadas de estudos. In: FÉRES-CARNEIRO, Terezinha (org.). Casal e família: permanências e rupturas. São Paulo: Casa do Psicólogo.

Jablonski, B. (2010). A divisão de tarefas domésticas entre homens e mulheres no cotidiano do casamento. Psicologia: ciência e profissão/Conselho Federal de Psicologia. (2), ano 30, pp. 262-275.

Kaufmann, J.-C. (2004). L'invention de soi: une théorie de l'identité. Paris: Armand Colin.

Kaufmann, J.-C. (2007a). Sociologie du couple. 4⿳亠丷厂 edição. Paris: PUF.

Kaufmann, J.-C. (2007b). L'entretien compréhensif. Paris: Armand Colin.

Lalive D’Epinay, C.; Bickel, J.F.; Cavalli, S.; Spini, D. (2005). Le parcours de vie: émergence d'un paradigme interdisciplinaire. In: J.F. Guillaume. Parcours de vie: regards croisés sur la construction des biographies contemporaines. Liège (Bélgica): Les éditions de l'université de Liège.

Losada, B. L.; Rocha-Coutinho, M. L. (2007 - set./dez.). Redefinindo o significado da atividade profissional para as mulheres: o caso das pequenas empresárias. Psicologia em Estudo, 12 (3), 493-502.

Maluf, M.; Mott, M. L. (2008). Recônditos do mundo feminino. In: F.A. Novais \& N. Sevcenko (orgs). História da vida privada no Brasil 3 - república: da belle époque à era do rádio. São Paulo: Companhia das Letras.

Mannheim, K. (1982). A questão das gerações. In: M. M. Foracchi (org.), Sociologia. São Paulo: Ática.

Martucelli, D. \& Singly, F. (2009). Les sociologies de l'individu. Paris: Armand Colin.

Mello, J. M. C. \& Novais, F. A. (2010). Capitalismo tardio e sociabilidade moderna. In: F. A. Novais \& L. M. Schwarcz. (orgs). História da vida privada no Brasil 4: contrastes da intimidade contemporânea. São Paulo (Brasil): Companhia das Letras.

Rocha-Coutinho, M. L. (1994). Tecendo por trás dos panos: a mulher brasileira nas relações familiares. Rio de Janeiro: Rocco.

Rocha-Coutinho, M. L. (1998). A análise do discurso em psicologia: algumas questões, problemas e limites. In: $\mathrm{L}$. Souza, M. F. Quintal de Freitas, \& M. M. P. Rodrigues (Orgs.), Psicologia: reflexões (im)pertinentes. São Paulo: Casa do Psicólogo. Rio de Janeiro: Rocco.

Rocha-Coutinho, M. L. (2005a). O papel de homens e mulheres na família: podemos falar em reestruturação? Psicologia Clínica, 15 (2), 93-108.

Rocha-Coutinho, M. L. (2005b). Variações sobre um antigo tema: a maternidade para mulheres com uma carreira profissional bem sucedida. In: T. Féres-Carneiro (org.). Família e casal: efeitos da contemporaneidade. Rio de Janeiro: Ed. PUC-Rio.

Rocha-Coutinho, M. L. (2007). Família e emprego: conflitos e expectativas de mulheres executivas e de mulheres com um trabalho. In: Féres-Carneiro, Terezinha (org.). Família e casal: saúde, trabalho e modos de vinculação. São Paulo: Casa do Psicólogo.

Scavone, L. (2001, fevereiro). Maternidade: transformações na família e nas relações de gênero. Interface comunicação, saúde, educação, 5 (8), 47-59. 
Recuperado em: 14 de agosto de 2010 de http://www.scielo.br/scielo.php?pid=s141432832001000100004\&script=sci_arttext

Singly, F. (2004). Fortune et infortune de la femme mariée. 2a edição. Paris: PUF.

Singly, F. (2005). Le soi, le couple et la famille. Paris: Armand Colin.

Widmer, E.; Levy, R.; Gauthier, J.A. (2006). Entre contraintes institutionnelle et domestique: les parcours de vie masculins et féminins en Suisse. In : Canadien Journal of
Sociology/Cahiers Canadiens de Sociologie, 31 (4), 461 a 462.

Recebido em 22/03/2012

Aceito em 11/09/2012

Endereço para correspondência: Carolina de Campos Borges. Rua Floriano Peixoto, 820/204, Bloco 2, Jardim América, CEP: 79803-050, Dourados-MS, Brasil. E-mail: carolinacambor@gmail.com. 